\title{
Cellulosic Sorption Filter Materials with Surface Flocculation Activity-A Hopeful Anticipation of Water Purification
}

\author{
Miloslav Milichovský, Břetislav Češek, Michaela Filipi, Jan Gojný \\ Institute of Chemistry and Technology of Macromolecular Materials, Department of Wood, Pulp and Paper, \\ Faculty of Chemical Technology, University of Pardubice, Pardubice, Czech Republic \\ Email: miloslav.milichovsky@upce.cz
}

Received December 20, 2013; revised January 16, 2014; accepted February 14, 2014

Copyright (C) 2014 Miloslav Milichovský et al. This is an open access article distributed under the Creative Commons Attribution License, which permits unrestricted use, distribution, and reproduction in any medium, provided the original work is properly cited. In accordance of the Creative Commons Attribution License all Copyrights (C) 2014 are reserved for SCIRP and the owner of the intellectual property Miloslav Milichovský et al. All Copyright (C) 2014 are guarded by law and by SCIRP as a guardian.

\section{ABSTRACT}

A filter media was developed comprising ionic activated cellulosic material with enormous sorption activity to ions-active dissolved and colloidal substances in aqueous systems evoking so-called surface flocculation and a filling material having a filter effect. The dilemma of the art of low sorption efficiency and high flow rate of filtrated aqueous dispersions without sacrificing its separation efficiency of fines has been solved by use of activated cellulosic material having multi-fold (roughly tenfold to hundredfold) sorption capacity for ions-active dissolved and submicron particulate contaminants compared to untreated cellulosic material.

\section{KEYWORDS}

\section{Nanotechnology; Cellulose Modification; Filtration; Surface Flocculation; Sorption}

\section{Introduction}

Water filtration was long viewed as merely a mechanical process of straining out the solid particles whereby turbid water is clarified. To function as a filter, the filter media must allow the fluid, commonly water or aqueous systems, flows through, while holding back the particulate contaminants. This holding back of the contaminants is accomplished by virtue of the operation, within the porous media, of one or both of two distinctly different filtration mechanisms, namely (firstly) mechanical sieving and (secondly) electrokinetic particle capture. In mechanical sieving, a particle is removed by mechanical entrapment when it attempts to pass through a pore smaller than itself. With this mechanism, filtration efficiency is controlled by the relative size of the contaminant and filter pore diameter. The efficient removal of very small particles, e.g., less than $0.1 \mu \mathrm{m}$ in diameter, therefore requires filter media with very small pore sizes for removal by mechanical sieving. Such finely pored filter sheets tend to have the undesirable characteristics of high-pressure drop across the filter sheet and short filter life. In the case of electrokinetic capture mechanism, the particle colloids are retained within the porous filter media by short-range attractive electrostatic forces.

Attempts to increase the short life of filter media due to pore blockage and enhance flow rates through filter media having small pores have been made by charge modifying the filter media by various means to enhance capture potential of the filter. It has long been recognized that adsorptive effects can enhance the capture of particulate contaminants. Commonly, it has been presumed that adsorption effect has neglecting influence upon filtration efficiency.

Sorption filtration [1] is a separation process prompting the cellulose and their derivate to offer new levels of performance in nanotechnology. Generally, the filtration processes are controlled by two mechanisms as follows:

1) By mechanical capture of separated particles;

2) By sorption forces between interacting particles, molecules etc. and walls of pores; i.e. by deposition. 


\section{Theoretical Background}

However, it has been appeared further possibility [1] as to solve the above mentioned dilemma of high separation efficiency vs. low flow rate of water through filter media and vice versa, i.e. surface flocculation effect $[2,3]$ in nanoscale of filter media pores. As depicted in Figure 1, soluble molecules, colloidal particles, etc. are attracted and concentrated around an active nanocentre $\mathrm{C}$ of porous material (see also Figure 2) and represented by pendant group of oligomeric character consisting of small active, e.g. cationactive, groups. Due to high concentration of captured interacting particles around the nanocentre $\mathrm{C}$, the micro-colloidal system is destabilised then followed by their flocculation.

\subsection{Sorption Filters}

Typical filter sheets are composed of fibres and mineral fillers with poly-dispersal size distribution character of their pores (see Figure 3). However, due to channelling effect the big pores are chocked stepwise because a flow of filtrated suspension is controlled by Equation (1), i.e. the flow is realised predominantly through the big pore.

$$
V \approx\left(\frac{1}{L_{e} \eta}\right) \cdot \int_{t} \int_{r e f}\left(r_{e f}^{4} \cdot f\left(r_{e f}\right) \cdot \Delta p\right) \cdot \mathrm{d} r_{e f} \cdot \mathrm{d} t
$$

$r_{e f}=2 / S$ radius of effective through flow pore;

$S$ : specific pore surface $(A / V) ; A-$ surface and $V-$

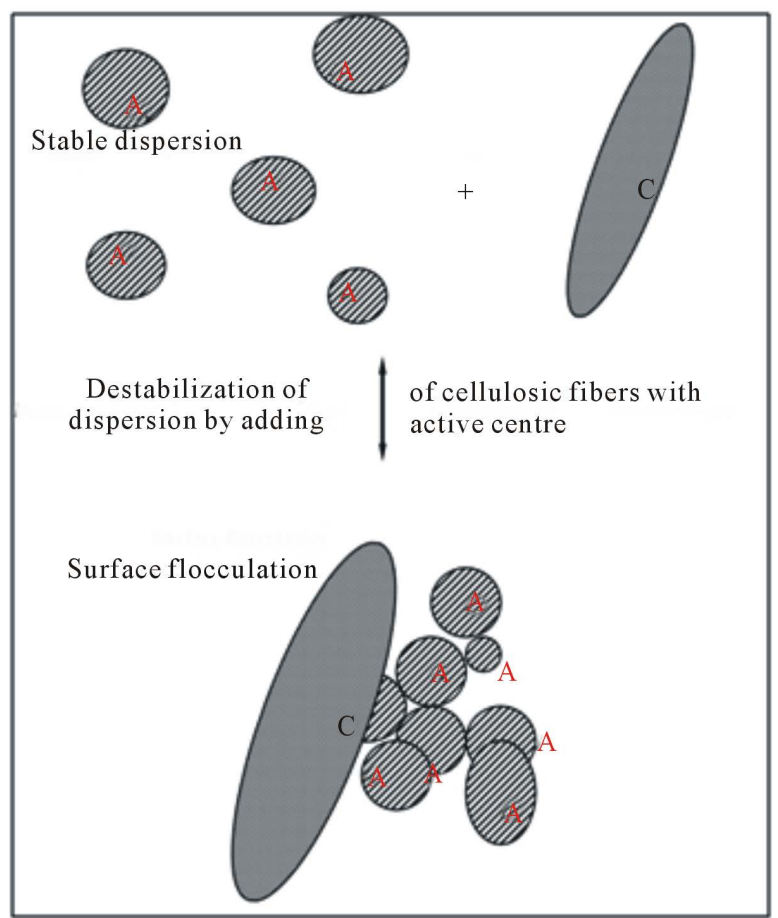

Figure 1. Representation of surface flocculation by use of activated pulp. Remark: A-polar active part of colloidal particle significantly interacting with active centre $C$.

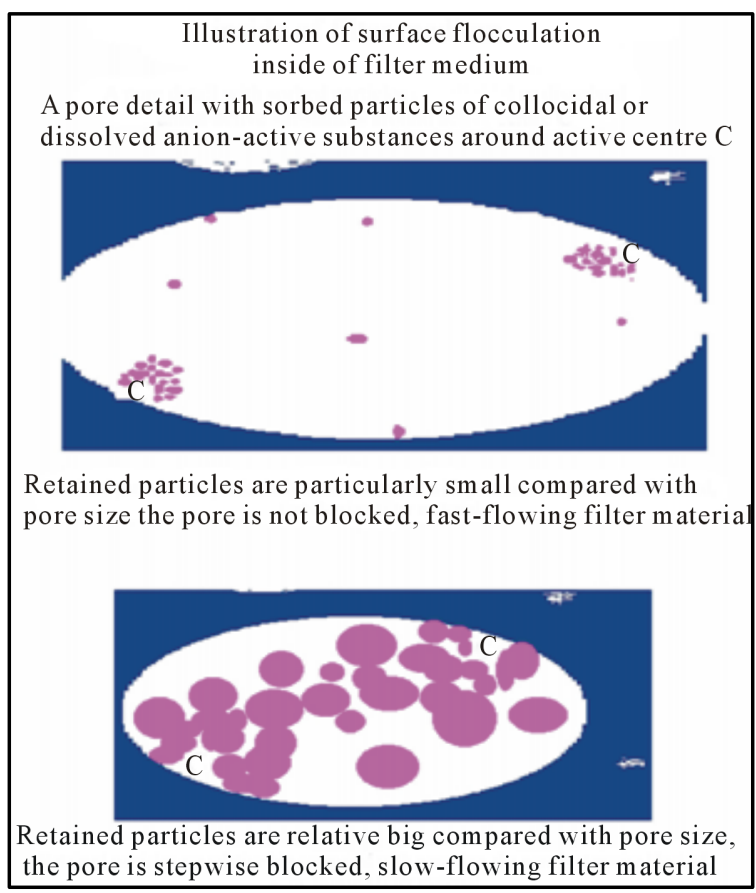

Figure 2. Representation of surface flocculation by use of activated pulp.

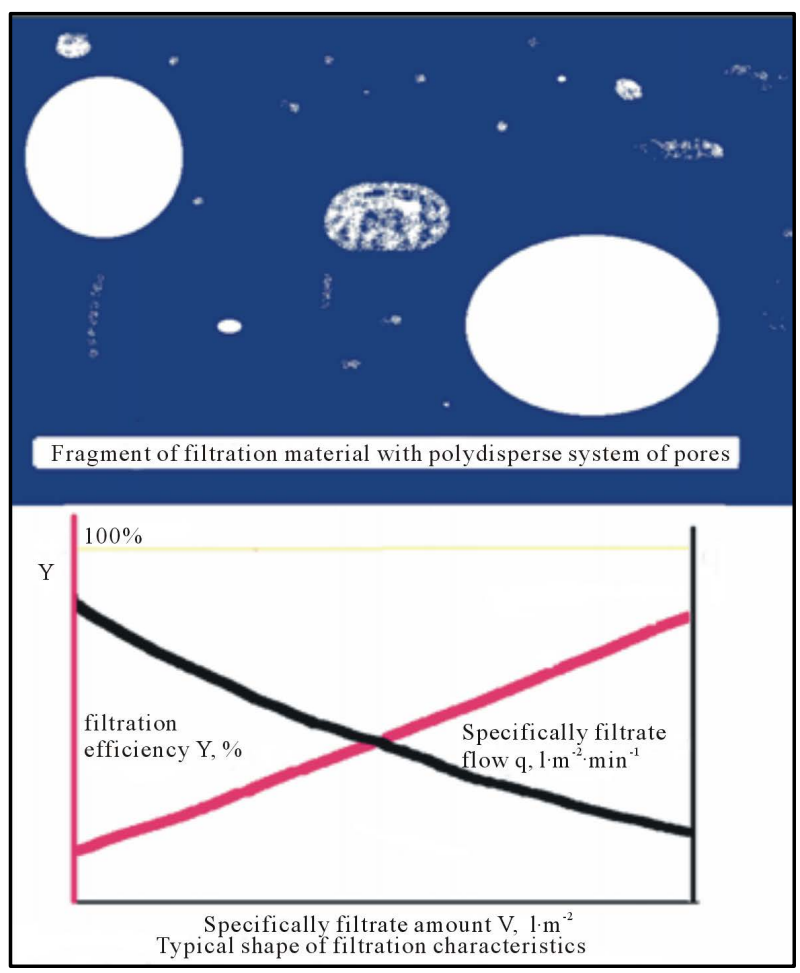

Figure 3. Sketchfragment of filtration material with polydispersal system of pores and typical filtration characteristics, filtration efficiency $Y$ and specifically filtrate flow $q$, vs. specifically filtrate amount $V$.

volume of the effective pore;

$L_{e}$ : effective through flow pore length (proportional to 
the thickness of the filter bed);

$\eta$ : viscosity coefficient.

As follows from this Equation (1), a quantity of volume filtered fluid by filter bed, $V$, is proportionally increased with 4-th power of the effective pore radius, $r_{e f}$, and this is proportional also to pressure gradient, $\Delta p$, and distribution function of pore size distribution in the sheet, $f\left(r_{e f}\right)$. It means that, if in the filter are also large pores, then the filtered liquid flows through the predominantly ones and so long as they progressively fill with separated particles. As resulted, the poly-dispersal character of pore size distribution is become more and more mono-dispersal. This behaviour is typical for the filter sheets controversially to cake filters such as almost mono-dispersals and filters.

Generally, we can classify the filtration materials as follows:

Filtration materials:

1) Slow-flowing (size of pores and separated particles are approximately the same);

2) Fast-flowing (size of pores are distinguishable bigger in comparison with the size of separated particles).

a) Pores of mono-dispersalsize distribution;

b) Pores of poly-dispersalsize distribution.

Chemical filter aids can be used to increase the filtration rate and/or to reduce the final cake concentration. Published experimental results indicate [4-7] that aggregation/dispersion condition, solid surface wettability [7] and surface tension of the liquid [4] play all important roles in filtration processes. A typical flow and filtration characteristic for both types of filtersheets is depicted in Figure 4. The removal of small particles in filter media by electrokinetical capture mechanism, i.e. by deposition, is depicted in Figure 5.

However, these filters are not able effectively to separate the dissolved and colloidal substances. In this case, a sorption filter is functioned because the molecules of dissolved and particles of colloidal contaminants are adsorbed and absorbed by pore surfaces and micro pores of the sorption filter, respectively. From this reason, the sorption filters are functioned for holding back of both dispersed and dissolved contaminants. The porous filter media, excepting of micro-porous polymeric membranes, known to the art as being suitable for the filtration of fine particle size contaminants are comprised of fibre-fibre or fibre-particulate mixtures formed dynamically into sheet by commonly papermaking methods from aqueous slurry and then subsequently drying the finished sheet. In those fibrous filter media that depend upon mechanical straining to hold back particulate contaminants, it is necessary that pore size of the filter medium be smaller than the particle size of the contaminant to be removed from the fluid. For removal of fine, submicron contaminant particles by both mechanical and electrokinetical capture, the

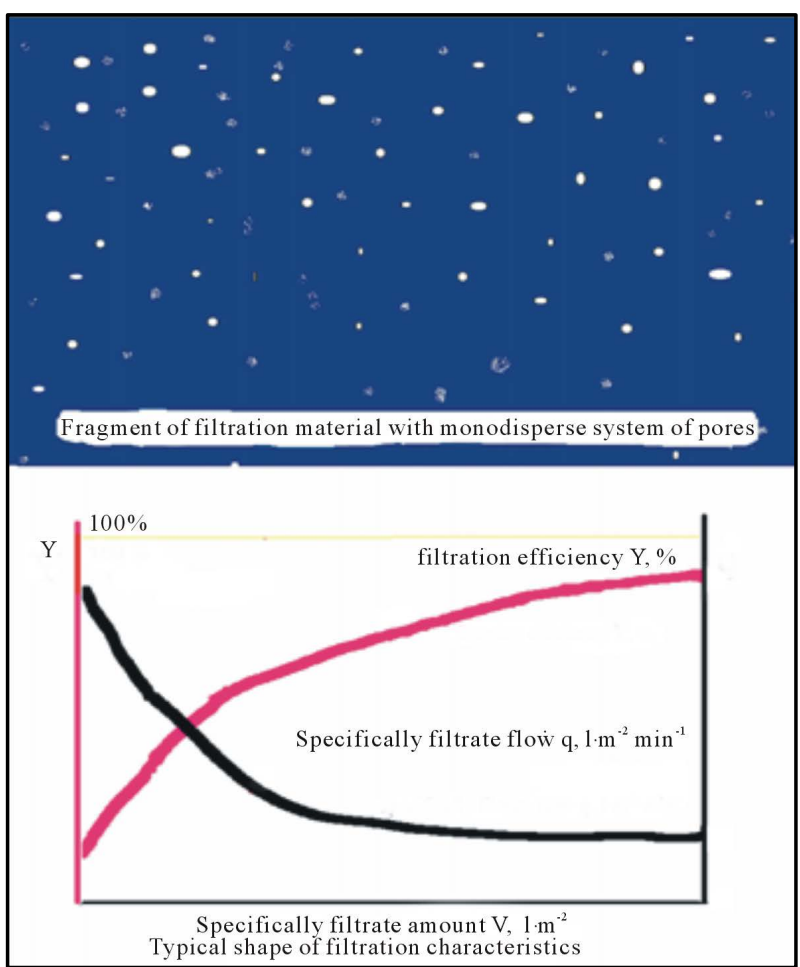

Figure 4. Sketch fragment of filtration material with approx. mono-dispersal system of pores and typical filtration characteristics, i.e. filtration efficiency $Y$ and specifically flow $q$ vs. specifically filtrate amount $V$.

filter media need to have correspondingly fine pores. Such the pore size of such a sheet is determined predominantly by the size and morphology of the materials used to form the sheet, it is necessary that one or more of the component materials have to be of a very small size such as small diameter of fibres.

As the size of the contaminants sought to be removed by filtration decreases, especially into the submicron range, the difficulty and expenses of providing suitably dimensioned fibre structures for optimum filtration by both mechanical and electrokinetical capture increases. Accordingly, there is considerable interest in the use of fine particulates such as diatomaceous earth. However, for such materials it is necessary to provide a matrix in order to receive a coherent handleable structure for commerce and industry.

It has also been suggested that an adsorptive sequestration, i.e. adsorptive deposition of particles by entry into capture within the pore channels, may be in some cases more important to so-called sterile filtration. This is consistent with the observation that bacterial pyrogen and virus particles may be removed by filtration through a membrane even though they are smaller than the pore sizes of commonly used 0.22 micro meter filters [8]. It is also described [9], that if the zeta potential of the pore walls of a membrane, e.g. nylon 66, and of the particles 


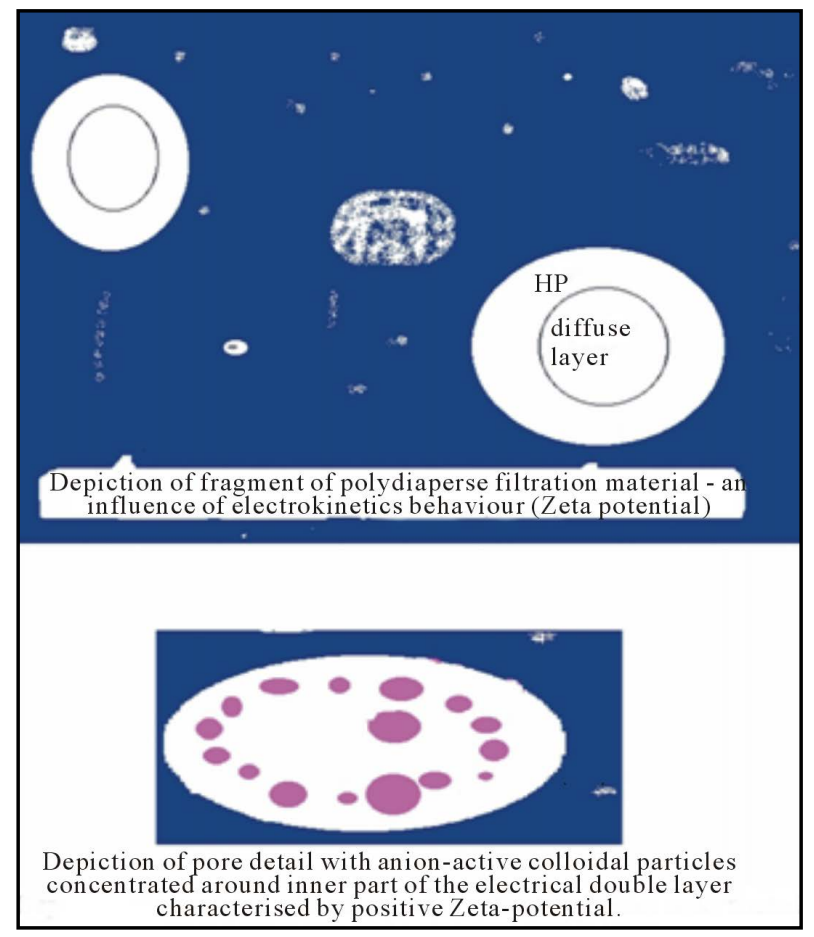

Figure 5. Sketch of sorptionfiltration material with polydispersal system of pores. Slow-flow filter sheet. Filtration by electrokinetical deposition mechanism. Remarks: 1) Separation process is controlled in the beginning phase of filtration by electrostatic forces. 2) Particles are concentrated around inner layer but in diffuse layer by action of weak electrostatic forces. 3) Sorption capacity is small. 4) Size of pores and separated particles is approximately the same. Pores are stepwise fulfilled by entrapped particles due to mechanical action.

are both low or if they are oppositely charged, the particle will tend to adhere to the pore walls, and the result will be removal of particles smaller than the pores of the filter.

Thus, at least one of the component materials in the sheet is a long, self-bonding structural fibre, to give the sheet with a sufficient structural integrity in both the wet and the final dried condition, to allow handling during processing and suitability for the end use. All sort of these traditionally filter materials are depicted as well as with the really sorption activity to dissolved and colloidal contaminants but their separation effect is low, because of low sorption capacity.

Cellulose and its derivate could be potentially suitable materials because cellulose is insoluble in water, renewable, biodegradable and biocompatible. Because of its abundance in nature, the cellulose is very suitable material for its cost effective technologies in ion exchange, affinity chromatography and membrane applications. However, the pure cellulose does not have sufficient amount of functional groups for effective metal ions, anionic colloids, or other charged particles removal effi- ciency. Refined and unrefined cellulose fibres such as wood pulp, cotton, cellulose acetate or rayon are commonly used. Wood pulp is most often used because of its low relative cost.

\subsection{Cellulosic Sorption Filters}

It is well known, that adsorption characteristic of chemical modified cellulose with regard to anionic or cationic compounds has been improved by introducing of the cationic quaternary groups $[10,11]$ or strong carboxylic groups, e.g. oxycellulose [12-14], respectively. For this reason, the monitoring both of the modification and adsorption processes has been done. Charge modified asbestos-free filter sheets with cellulose fibres are disclosed in DE Pat. 3,329,385. As disclosed therein, the use of cationic-modified cellulose, preferably 2-hydroxy-3-trimethyl ammonium propyl cellulose-chloride, and such a filter layer may have increased boundary-surface active properties, resulting in a substantial improvement in the separation of micro-organisms and being preferentially suitable for the retention of fine substances in the layer. The use of amidooximated cellulose or cellulosic materials for the removal of metalions and dyes from waste waters is described in [15-17]. This separation is based on adsorption activity of amidooximated cellulose due to formation of a complex between the amidooxime group and $\mathrm{Cu}(\mathrm{II}), \mathrm{Cr}(\mathrm{III}), \mathrm{Cd}(\mathrm{II})$ and $\mathrm{Ni}(\mathrm{II})$ ions.

\subsection{Sorption Isotherms}

Adsorption behaviour of colloidal particles and metal ions is well described by use of Langmuir isotherm though other isotherms exist $[3,13]$. The affinity of ions to oxycellulose is in order [13]: $\mathrm{Cd}^{2+}>>\mathrm{Ca}^{2+}>\mathrm{Mg}^{2+}>>$ $\mathrm{Na}^{+}$. These findings are in full agreement with ion-exchange batch experiments by use of amidooximated cellulose [15]. It is logical that uptake of monovalentcations are much lower than of divalent cations. Affinity of $\mathrm{Na}^{+}$ to oxycelluloseis nearly zero in presence of divalent cations. However, an even more complication situation arises in more diluted solutions (concentration < approximately $10^{-4}$ to $10^{-5} \mathrm{~mol} / \mathrm{l}$ ) in admixture with other substances especially with the colloid activity as Fe(II) or Fe(III) and dissolved oxycellulose. These competing interactions complicate the overall adsorption process and influence its final course. The sorption isotherm displays then an adsorption isotherm with a sigmoid shape possessing a longer initial phase followed by a smaller slope and a consequent smaller adsorption capacity [12]. The overall adsorption process is quite complex since several parallel reactions occur:

1) The adsorption itself, which involves the reaction of the superficial groups on the sorbent surface with the sorbed substances in the interface of the highly hydrated 
cellulose fibres;

2) The direct reaction of the sorbed substances with the molecules andmicrogel particles in the solution.

The adsorption capacity of the sorbent depends not only on the affinity of the sorbent towards the molecules and nano-particles of the sorbed substances but it is mainly defined by the concentration and accessibility of adsorption centres. The adsorption capacityis higher at more spongy structures developed by an erosive process of originally compact hydrogel substance of cellulose in amorphous and gradually even crystalline more oriented areas and their ability to induce their following interactions leading to superficial flocculation [3]. The overall together are influenced by soluble or colloidal cellulosic substances being ceaselessly released into water [18], i.e. especially in the case of strongly degraded oxycellulose.

\subsection{Kinetics of Sorption Processes}

Realy filtration process introduces a dynamic process comprising competing interactions where kinetic of sorption process play an important role. The kinetic of these sorption processes was satisfactory verified by use of following theoretical function (2) predicted by simple diffusion model [13]:

$$
c_{a}=\frac{n_{a} \cdot t}{\left(K \cdot n_{a}+t\right)}
$$

where $n_{a}$ and $c_{a}$ are concentration of adsorbed components retained by oxycellulose, pulp etc. at time $t \rightarrow \infty$ and $t$, respectively. The parameter $K=k / D$ is proportional to reciprocal value of diffusion coefficient $D$ of adsorbed metals into cell-wall of oxycellulose. Obviously, as it follows the Equation (2), it is true that $\lim _{t \rightarrow \infty} c_{a}(t)=n_{a}$.

The values of slopes of linear dependences $t / c_{a}$ vs. $t$ in prove satisfactory this behaviour because these values increase with reciprocal values of adsorbed amount $n_{a}$ of $\mathrm{Cd}^{2+}$ and the resulted values of $n_{a}$ from kinetic measurements are in satisfactory agreement with results of adsorption measurements [13]. This behaviour confirms that the diffusion into micro-thin surface layers of cell-wall of natural oxycellulose is the dominant process controlling the sorption kinetics. Moreover, verification of the kinetic measurements enables us to characterise the mechanism of the sorption process. The intercepts of these linear dependences $K$ are proportional to the distancein the cell-wall to which the adsorbed component has penetrated at steady-state (the mean depth of penetration $x_{r a}$ ) and to the reciprocal value of adsorbed concentrations $n_{a}$, because $k=x_{r a}^{2} / n_{a}$. This behaviour is similar as the kinetics of vapour diffusion and condensation in porous cellulosic fibre web formation, e.g. paper [19]. Therefore, it is possible to conclude that the adsorption process does not take place strictly on the surface of oxycellulose but instead is followed by diffusion to a limited depth of its cell-wall. Obviously, if $D$ is constant, then the steadystate depth of diffusion in the eroded cell-walls of oxycellulose (i.e. $x_{r a}$ ) is independent of the metal ions concentration in an aqueous solution.

The main drawback of these approaches is a relatively low sorption capacity of the above mentioned filter media enabling, practically, no substantially increase the flow rate of water without sacrificing their separation efficiency of fine contaminants. Further, as well known (see CS Pat. 167,010), the optimal conditions of cationic-modification of cellulosic materials, i.e. the reaction of cellulosic materials with 2,3-epoxy propyl-trimethyl ammonium chloride, are complicated by requirement of minimum temperature of the reaction slurry to be at least $40^{\circ} \mathrm{C}$. Certainly, to ensure this requirement is complicated and disadvantageous both from economical and practical reasons.

\subsection{Cellulosic Sorption Filters with Surface Flocculation Ability}

A cellulosic sorption filter material with surface flocculation activity attains new levels in cellulose nanotechnology. We have published [2,3] results which demonstrate enormously increase of sorption capacity of such cationic-activated cellulosic materials with respect to anion-active substances of soluble or colloidal character due to their surface flocculation activity (see Figure 1). The term "anion-active" is employed since both anionic and non-anionic forms may occur in dependence under the experimental conditions employed, e.g. $\mathrm{pH}$ of aqueous fibre slurry.

This behaviour can be achieved by the use of water soluble non-colloidal activator of oligomeric character in an amount up to about $10 \%$ by weight of bone dry (b.d.) cellulosic material, which imparts to the filter sheet enhanced dissolved and dispersed particulate removal efficiencies over a broad $\mathrm{pH}$ range in aqueous fluids. The activating substances areepoxide-based water-soluble oligomers containing a substantial number of quaternary ammonium groups derived from any suitable aliphatic amine. Surprisingly, it was found that activation reaction between the cellulosic materials and these activators must meet no several requirements as usual involving time, temperature and optionally a catalyst. The activation reaction takes place at ambient temperature, i.e. as usual $15^{\circ} \mathrm{C}$ to $30^{\circ} \mathrm{C}$ and $\mathrm{pH}$ value from 7 to 9 , during approximately 30 to 70 minutes. The above-mentioned changes in the structure of cellulose have a significant effect on the sorption behaviour of cellulosic material [2]. However, in contrast with the usual a simple shape of adsorption isotherms it was observed a typical sigmoid character of these adsorption isotherms in the case of activated pulp by cationic oligomer groups and an- 
ion-active substances, e.g. dyestuffs [3].

This kind of adsorption is called as surface flocculation (see Figures 1 and 2), because free pendent cationic group from firmly fixed the oligomeric substance to fibre surface of cellulosic material represents an active centre being attracted the anion-active particles or molecules and this one enables the particles to aggregate, i.e. to flocculate. Many of polyamide-polyamine epichlorhydrine resins and charge modifiers as 2, 3-epoxy propyltrimethylammonium chloride require adaptation, because for the purpose of providing extended storage stability, the most of epoxide groups are chemically inactivated to premature cross linking of these substances. Thus, prior to the use of activator for above mentioned purposes the activator may be adapted into the more reactive state by regeneration of the epoxide groups. Typically adaptation entails adding sufficient aqueous caustic to a solution of the activator of a low chemical activity to convert the chemically inactive chlorohydrin form to the active epoxide form. The parts by weight of aqueous caustic per parts by weight of activator vary with the product and are specified by the manufacturer. The adaptation process is efficient and complete adaptation is generally achieved in about thirty minutes, whereupon the activator solution is suitable for use $[3,20]$.

The cellulosic sorption filter media sheets are prepared from aqueous slurry comprising cationic-activated cellulosic material with enormous sorption activity and optimised level of fine particles such as diatomaceous earth (kieselguhr) and/or perlite. It may be desirable to include a wet strength agent as a neutral $\mathrm{pH}$ curing polyamide-polyamine epichlorhydrine resin in an amount of up to about $2 \%$ by weight of the finished filter medium. The filter sheets may be prepared from this aqueous slurry by a convential papermaking process, e.g. using a Fourdrinier forming wire and the like, and drying, or the filter moulded sheets may be prepared by suitable papermaking process such as, for example, vacuum felting upon suitable moulded wire formation, and drying. A special feature of this preparation is the provision of filter media sheet in which the level of a fine particles retained is enhanced as compared to the sheet prepared conventionally.

The cellulosic material comprises cotton, rayon and pulps such as unbleached or bleached hardwood and softwood sulphate pulps, or unbleached or bleached softwood sulphite pulps as well as the pulps with high amount of alpha cellulose (more than 95\% alpha cellulose) on one hand or the pulps with high lignin contents such as groundwood, Thermo Mechanical (TMP) and Chemical Thermo Mechanical (CTMP) Pulps on other hand, or mixture of these ones which is in at least of one of a fibrous, micro fibrous, granulated and pulverized form having a beating degree of substantially 15 to 70 SR (according to Schopper-Riegler) and which is chemically bounded with a cationic activating substance-activator (in amount up to about $10 \%$ by weight of bone dry cellulosic material). Such a filter sheet may have increased sorption activity, resulting in a substantial improvement in the separation of dissolved and colloidal substances of anion-active character in the filter sheet. The filter sheet also has excellent sorption capacity in dependence on the dosed amount of the activator (e.g. see Figure 6). A further advantage of the cellulosic sorption filter sheet lies in an improved clarifying effect while maintaining good through flow performance (see Tables 1 and 2).

\section{Description of Experiments}

\subsection{Used Materials}

1) Softwood bleached sulphite pulp and hardwood bleached sulphate pulp both separately defibered and beaten at $3 \%$ consistency.

2) Commercial perlite was utilised as the filling material and commercial cationic polyamine-polyamide epichlorhydrin resin as wet strength improving additive.

3) The quaternary oligomeric activator in non-adapted form contained $3.0 \%$ of epoxy-groups and $4.6 \%$ of epoxy-groups in adapted form. Adaptation was done by carefully mixing 2 parts by weight of commercial activator with 1 part by weight of dissolved natrium hydroxide of $10 \%$ concentration. The adaptation reaction was finished after 30 minutes of slowly stirring by reaction admixture of temperature at $40^{\circ} \mathrm{C}$.

4) Pigment anionactive black dyestuff as test contaminant with a particle size distribution of $4 \%<10 \mathrm{~nm}$ and approx. $60 \%<100 \mathrm{~nm}$.

\subsection{Preparation of Filter Sheets}

Series No. 1

Table 1. Composition of the sorption filters.

\begin{tabular}{cccccc}
\hline Sheet No. & Hardwood Pulp wt.\% & Softwood Pulp wt.\% & Perlite wt.\% & Wet Strength Agent wt.\% & Activator Adapted wt.\% \\
\hline 1 & 30 & 50 & 20 & - & - \\
2 & 30 & 50 & 20 & 1.5 & - \\
3 & 30 & 50 & 20 & 1.5 & 5 \\
4 & 30 & 50 & 20 & 5 \\
\hline
\end{tabular}


Table 2. Filter performance characteristics of tested filters.

\begin{tabular}{ccccccccc}
\hline & \multicolumn{2}{c}{ Sheet No. 1 } & \multicolumn{2}{c}{ Sheet No. 2 } & \multicolumn{2}{c}{ Sheet No. 3 } & \multicolumn{2}{c}{ Sheet No. 4 } \\
\hline$V_{s}\left(\mathrm{l} \cdot \mathrm{m}^{-2}\right)$ & $\mathrm{Y}(\%)$ & $\mathrm{q}_{50}\left(\mathrm{l} \cdot \mathrm{m}^{-2} \cdot \mathrm{min}^{-1}\right)$ & $\mathrm{Y}(\%)$ & $\mathrm{q}_{50}\left(\mathrm{l} \cdot \mathrm{m}^{-2} \cdot \mathrm{min}^{-1}\right)$ & $\mathrm{Y}(\%)$ & $\mathrm{q}_{50}\left(\mathrm{l} \cdot \mathrm{m}^{-2} \cdot \mathrm{min}^{-1}\right)$ & $\mathrm{Y}(\%)$ & $\mathrm{q}_{50}\left(\mathrm{l} \cdot \mathrm{m}^{-2} \cdot \mathrm{min}^{-1}\right)$ \\
\hline 177 & 48.4 & 346 & - & - & 96.3 & 364 & 94.8 & 358 \\
350 & 2.6 & 345 & 13.8 & 449 & 95.8 & 301 & 95.0 & 301 \\
704 & - & - & 10.4 & - & 92.3 & 215 & 92.4 & 220 \\
760 & - & - & 8.8 & - & 89.0 & 203 & 91.3 & 198 \\
1592 & - & - & 5.0 & - & 75.6 & 154 & - & - \\
1769 & - & - & 4.0 & 429 & 73.1 & 152 & - & - \\
\hline
\end{tabular}

Remark: $V_{s}$ specifically filtrate amount; $Y$ filtration efficiency; $q_{50}$ specifically filtrate flow at filtration pressure of $50 \mathrm{kPa}$.

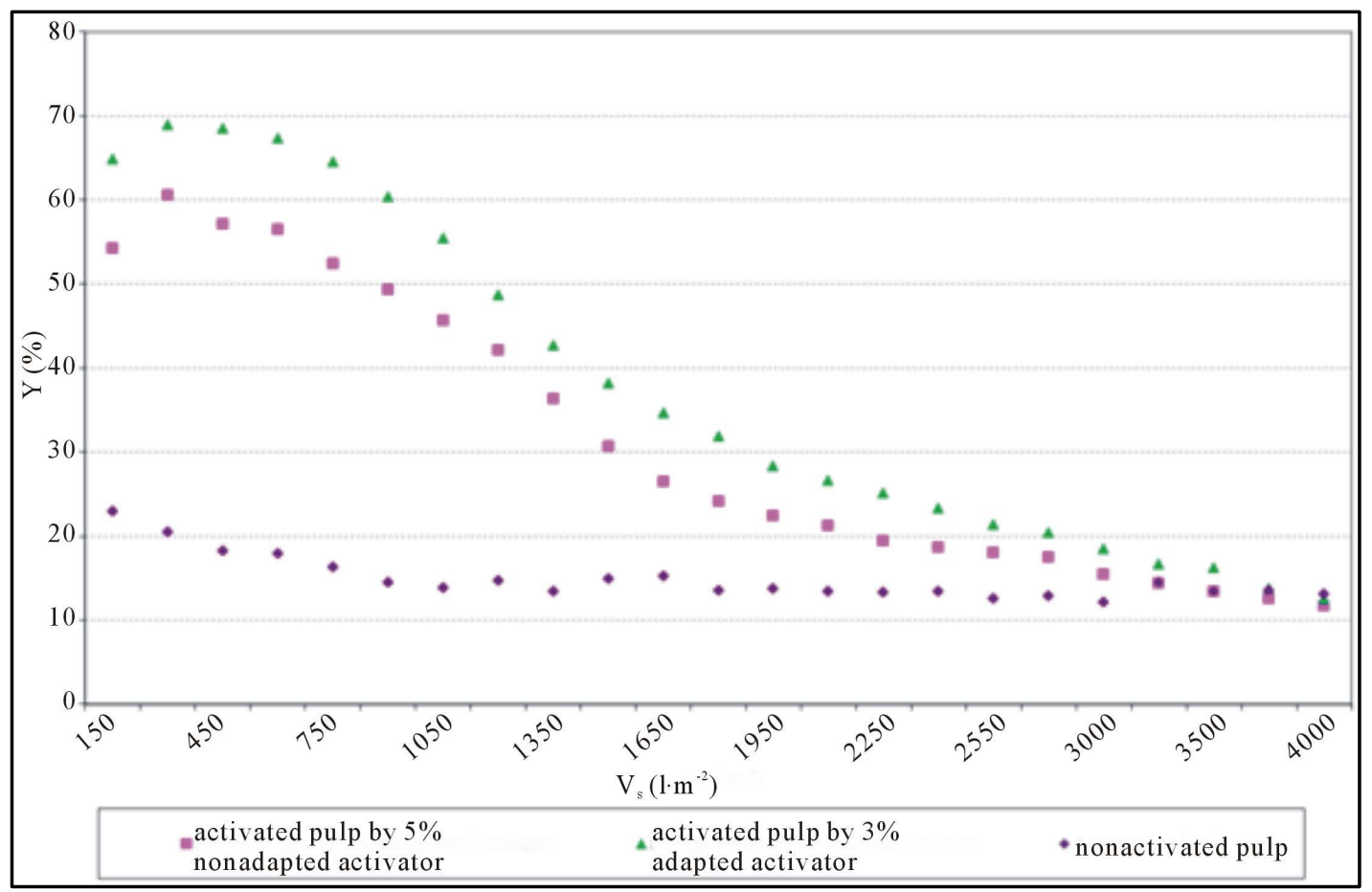

Figure 6. Separation efficiency vs. specifically filtrate amount. Fast-flow filters sheets with and without activated cellulosic materials.

A series of filter sheets were prepared utilizing softwood bleached sulphite pulp defibered and beated at 3\% consistency to a beating degree equal to $18 \mathrm{SR}$ followed by addition:

1) $5 \%$ non-adapted activator by weight of b.d. pulp;

2) $3 \%$ adapted activator by weight of b.d. pulp;

3) No activator.

And $1.5 \%$ wet strength agent were added by weight of b.d. finished filter medium. The components were added to an aqueous slurry of $\mathrm{pH}=8.0$ during strong agitation. After 40 minutes of slow agitation the slurry was subsequently diluted to 0.5 percent consistency and the filter sheets were prepared by use of conventional papermaking process. Results are set forth in Figure 6.

$\underline{\text { Series No. } 2}$
A series of runs were conducted in the manner of Series No.1, employing as the cellulosic material the softwood bleached sulphite pulp and hardwood bleached sulphate pulp both separately defibered and beaten at 3\% consistency to a beating degree of 22SR and as the filling material $20 \%$ by weight of perlite. The wet strength additive was dosed in amount $1.5 \%$ by weight of b.d. finished filter medium. The quaternary oligomeric activator in adapted form as described above in Series No. 1 was dosed in amount $5 \%$ by weight of b.d. cellulosic material. Separately composition of conducted runs is summarised in Table 1.

The additives were added to an aqueous slurry at $\mathrm{pH}=$ 7.5 during strong agitation of pulp slurry at consistency $3.0 \%$ before an addition of perlite. After 60 minutes of 
moderately agitation was the slurry subsequently diluted to 0.5 percent consistency and the filter sheets were prepared by use of conventional papermaking process.

\subsection{Filter Tests}

The filter media sheets were subjected to the same examinations, namely with water and with contaminated liquid. The experiments with contaminated liquid-pigment anionactive black dyestuff as contaminant of concentration $10 \mathrm{mg} / \mathrm{l}$ of water-took place on a filter area 30 square centimetres with a filtration pressure of 50 and $150 \mathrm{kPa}$. Before every measurement a filter pad was washed out 5 minutes by tap water with a pressure 50 $\mathrm{kPa}$ as well as water flow rate was estimated. The quantity of liquid passing through the filter area-measured as a specifically filtrate amount, $V_{s}\left(\mathrm{l} \cdot \mathrm{m}^{-2}\right)$ - under these condition and effluent dyestuff concentration was measured. Filtration efficiency $Y(\%)$ was then expressed as percent separation efficiency when compared to the inlet concentration of coloured water, calculated using Equation (3).

$$
Y=\frac{\text { concentrationin }- \text { concentrationout }}{\text { concentrationin }} \times 100
$$

The water flow rate at start of experiments was in all experiments approximately the same at comparable condition and composition of filter sheets, i.e. at filtration pressure $150 \mathrm{kPa}$ with samples of Series No. 2, $70 \pm 12$ $\mathrm{m}^{3} \cdot \mathrm{m}^{2} \cdot \mathrm{h}^{-1}$. Both filtration efficiency, $Y(\%)$ and specifically filtrate flow rate, i.e. $\mathrm{q}_{50}\left(1 \cdot \mathrm{m}^{-2} \cdot \mathrm{min}^{-1}\right)$ at a filtration pressure of $50 \mathrm{kPa}$ vs. specifically filtrate amount, $V_{s}$ $\left(1 \cdot \mathrm{m}^{-2}\right)$, was measured.

Further experiments similar to both Series No. 1 and No. 2 were performed but with different composition of aqueous slurry and different pulp beating. Received results are presented in Figures 7 and 8.

\section{Results Description and Evaluation}

The improvement in filtration performance with activated pulp is dramatic with decreasing tendency, because a depletion of sorption capacity of activated cellulosic material. However, as follows from received results, the improvement in filtration performance with pulp activation is strongly dependent upon type of used filter sheetslow-flowing and fast-flowing filter sheets have the different filtration characteristics as well as different these characteristics we have to expect for filtration materials with poly-dispersal and approximately mono-dispersal system of pores. According to received results we can divide the sorption materials with surface flocculation activity as follows:

1) Filters, with typical filtration characteristics for fastflowing filter materials with poly-dispersal system of pores, which size is enormously big in comparison with entrapped particles, are illustrated in Figure 9-no remarkable filter filling by separated particles is appeared (compare with results in Figure 6);

2) Filters with typical filtration characteristics for slow-flowing filter materials with poly-dispersal system

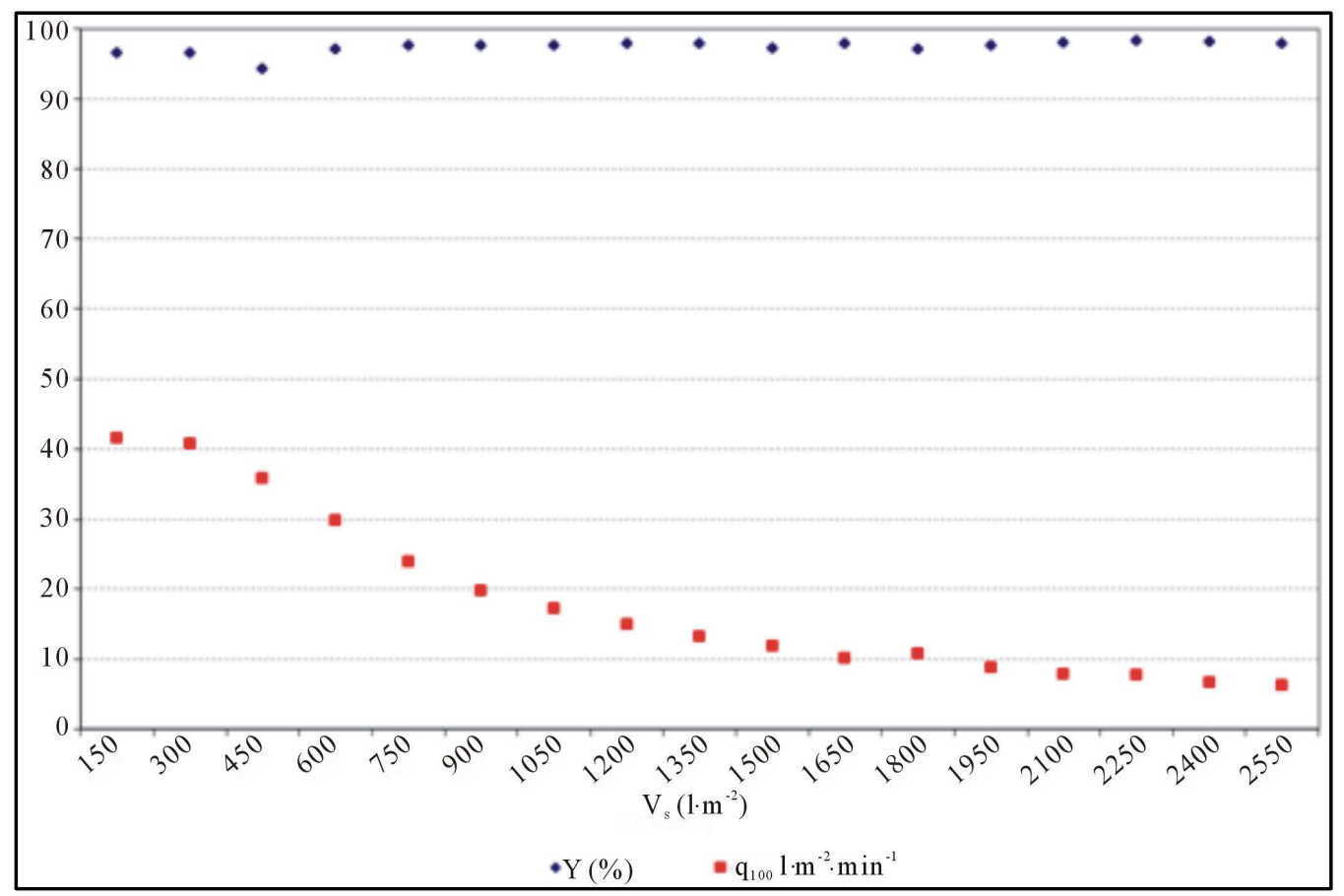

Figure 7. Separation efficiency and specifically filtrate flow vs. specifically filtrate amount. Slow-flow filter sheet, poly-dispersal system of pores composed of activated cellulosic material. 


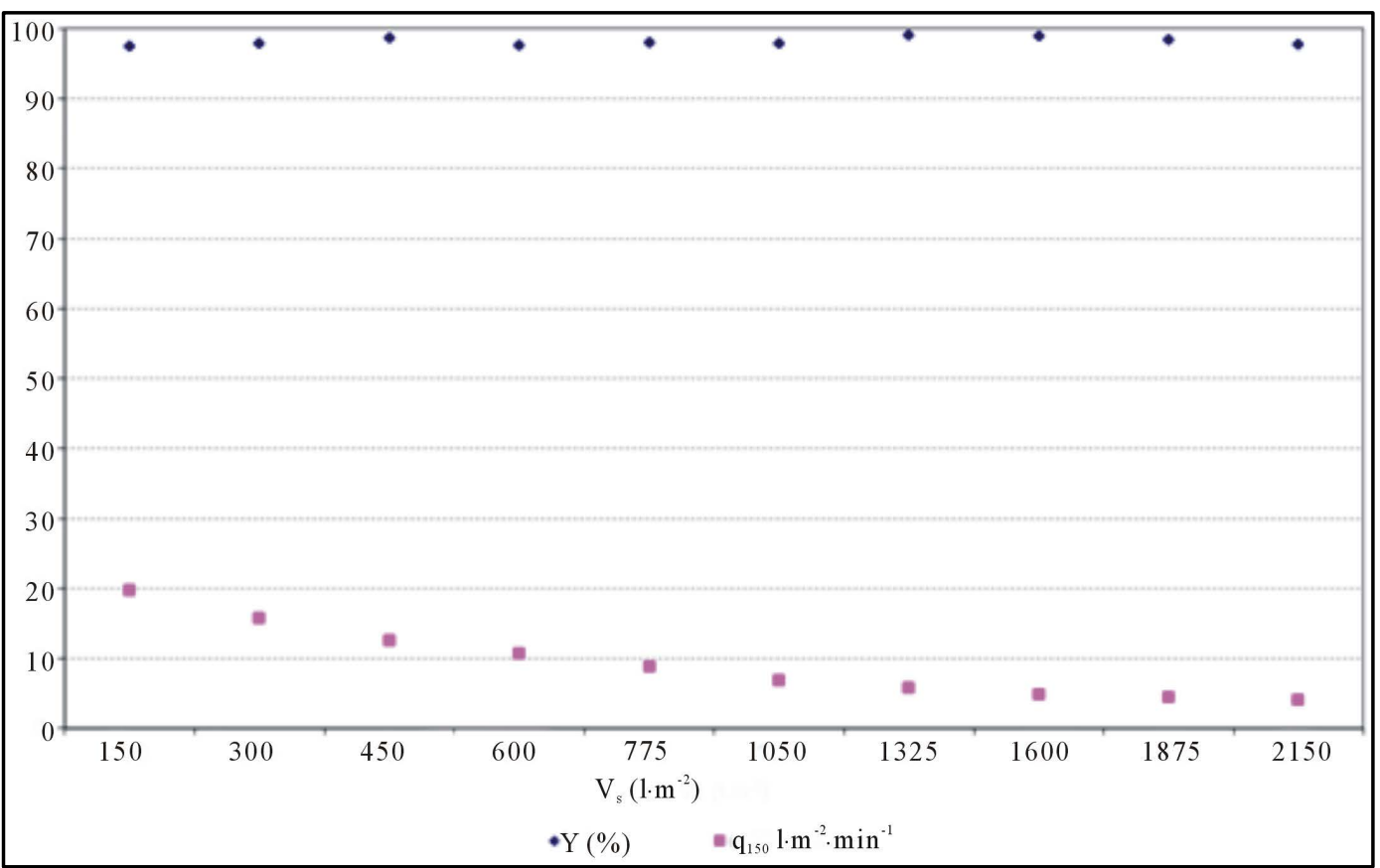

Figure 8. Separation efficiency and specifically filtrate flow vs. specifically filtrate amount. Slow-flow filter sheet, approximately mono-dispersal system of pores composed of activated cellulosic material.

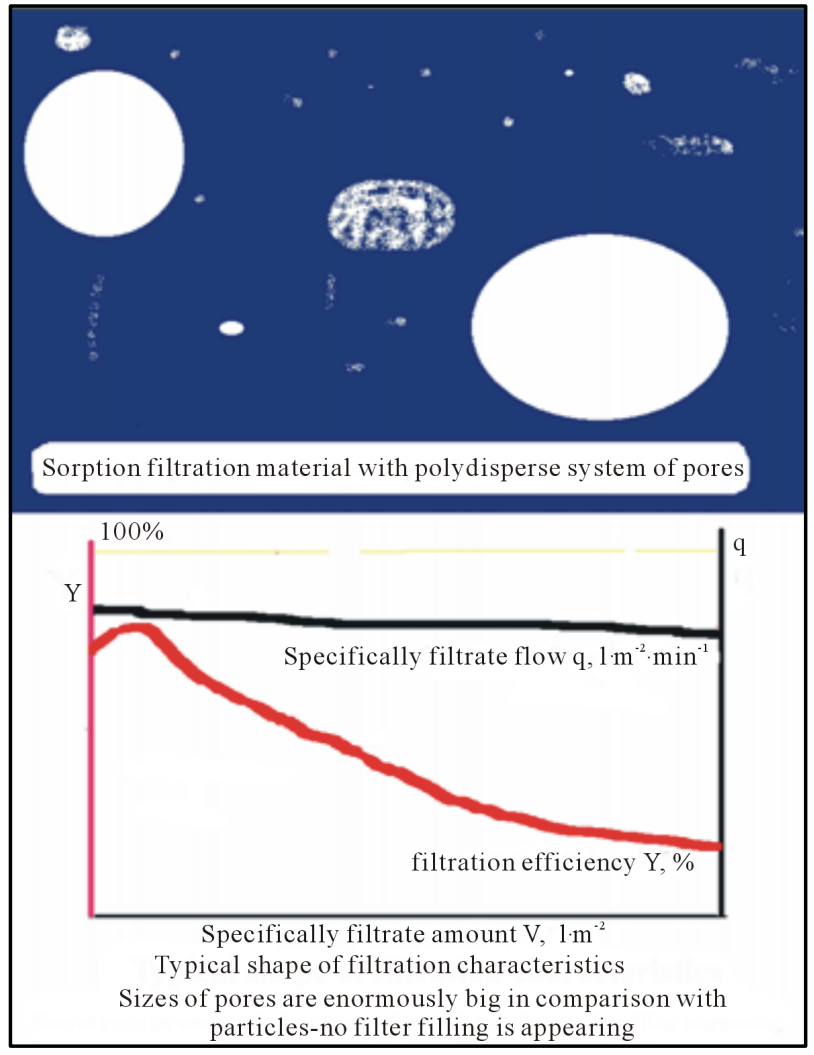

Figure 9. Sketch of sorption filtration material with polydispersal system of pores (Fast-flow filter sheets).

of pores, which size is approximately comparable with size of particle, are illustrated in Figure 10—stepwise filter blocking (compare with results in Figure 7);

3) Filters with typical filtration characteristics for slow-flowing filter materials with approximately monodispersal system of pores, which size is comparable with size of particles, are illustrated in Figure 11-stepwise filter blocking (compare with results in Figure 8).

The explanation of this above mentioned behaviour resulting for both slow-flowing and fast-flowing sorption filter materials with surface flocculation activity is demonstrated in Figure 2.

The slow-flowing sorption filters (see Figure 10) are depicted by following typical manners:

1) Separation process is controlled especially in the beginning phase of filtration by sorption phenomenon.

2) Active centres are firmly bonded with cellulosic substrate.

3) Surface flocculation is evoked around the active centres.

4) Sorption process is controlled by isotherm with extreme sorption capacity.

5) Pores are stepwise fulfilled by entrapped particles.

On the other hand, the fast-flowing sorption filters with surface flocculation activity (see Figure 6) are depicted by typical following manners:

1) Separation process is controlled especially in the beginning phase of filtration by sorption phenomenon.

2) Active centres are firmly bonded with cellulosic substrate.

3) Surface flocculation is evoked around the active centres. 


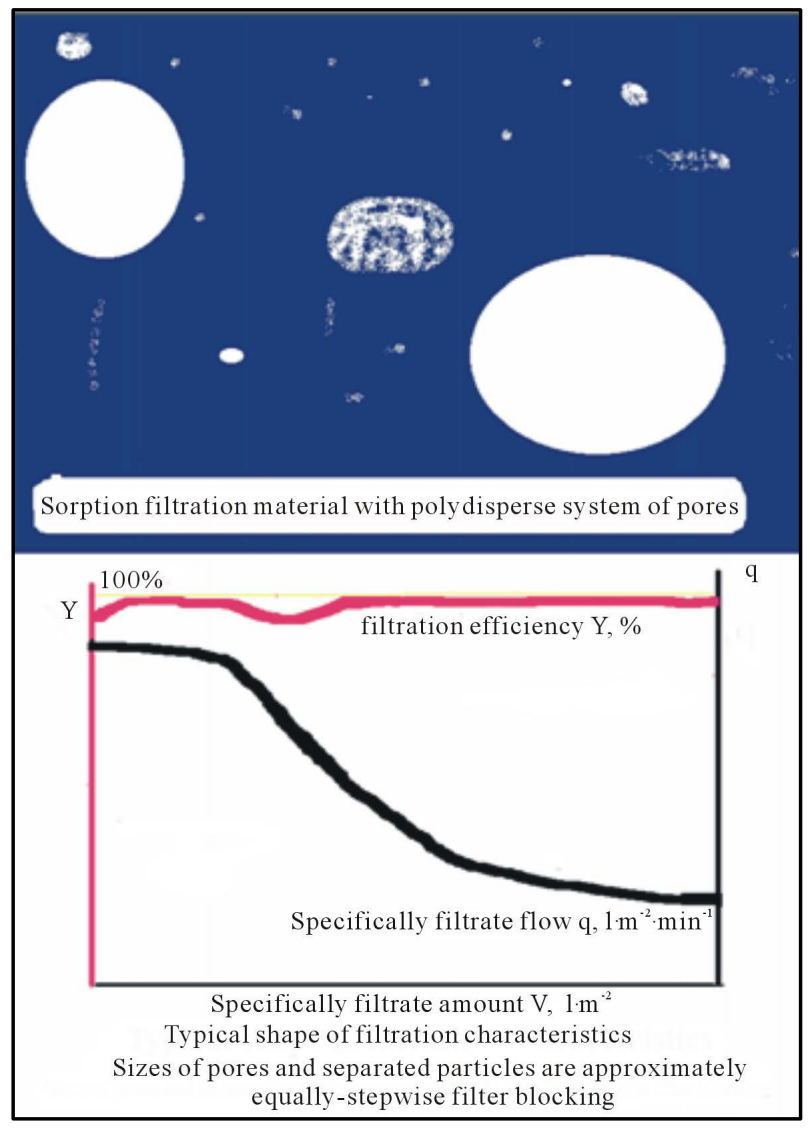

Figure 10. Sketch of sorption filtration material with polydispersal system of pores (Slow-flow filters sheets).

4) Sorption process is controlled by isotherm with extreme sorption capacity.

5) Pores are not fulfilled.

Also a filter media was developed comprising filling material having a filter effect and anionic activated cellulosic material-oxycellulose-with high sorption activity to cation-active dissolved especially metal ionsand similar colloidal substances in aqueous systems evoking so-called surface flocculation (see Figures 1 and 5). However, the adsorption processes are more complicated and influenced by solubility of oxycellulose, its composition and character of released components in supernatant and also by a presence of other competitive substances and ions in the aqueous solutions. The adsorption capacity of oxycellulose increases with the increase of $\mathrm{COOH}$ group content and is distinctly increased by presence of other competitive ions in the solution, e.g. $\mathrm{Fe}^{2+}$ and $\mathrm{Fe}^{3+}$ ions [12].

By simple oxycellulose modification it is possible to prepare amphoteric derivatives of anionic oxycellulose by use of a common and commercial quaternizing agent contains diepoxy propyl dimethyl ammonium chloride. However, the sorption behavior so modified cellulose is strongly influenced by $\mathrm{pH}[21,22]$.

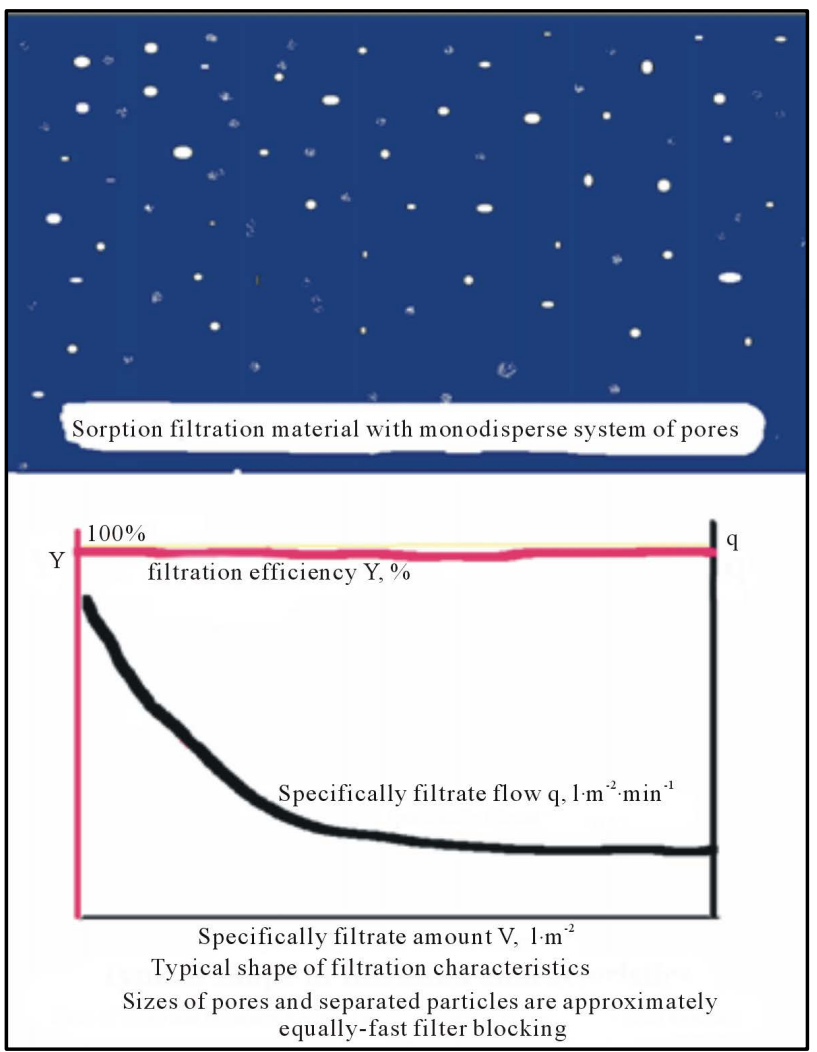

Figure 11. Sketch of sorption filtration material with approximately mono-dispersal system of pores (Slow-flow filters sheets).

Additionally, by connecting with this phenomenon it is expected further developments in nanotechnology of papermaking and similar processes, because sorption filtrations enable us to control the interaction of useful molecules and colloidal particles in nano-space around suitable activated centres in micro- and macro-pores of paper materials. At first, it is all sorts of water treatment processes.

Generally, a flow of water with other components inside of living matter provides the basic processes of its existence. The soluble and colloidal substances are flocculating around pendent oligomeric groups in nano-space inside of pores being controlled bynano-processes of bottom up character, i.e. by composition of interface compared with the composition of water environment. The nano-processes in living organisms do not occur independently but they are part of a larger organized biostructure with the ability to control, use, and if necessary, are realigned for its higher purpose.

As depicted in Figure 12, due to the very low concentrations of the constituents $A$ in the media (water) molecular reactions not occur leading to the formation of the product $P$ (the reaction No. 1 ). The influence of the active ingredient $C$ firmly associated with the interface of the substrate, however, provides an accumulation and, 


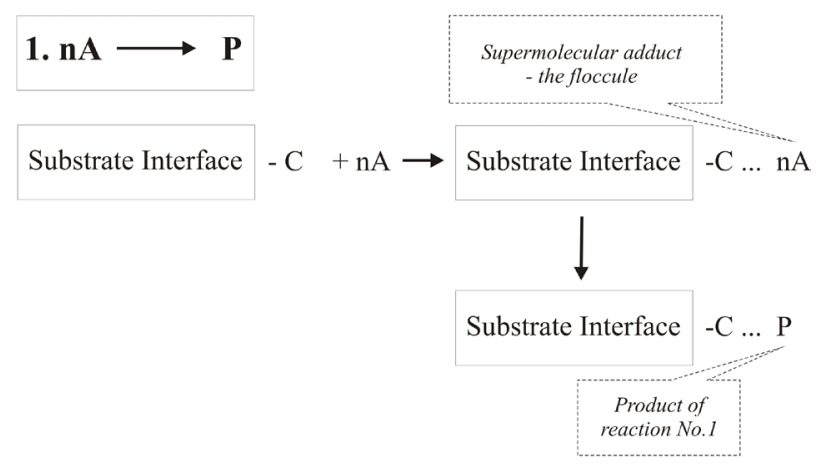

Figure 12. Schematic depiction the principle of the use of surface flocculation for controlled supermolecular-chemical reactions and processes.

where necessary, appropriate the orientation of the molecules $A$, nano-particles etc. in nano-space around active centre $C$, followed by invokes so relevant reactions or supermolecular interactions to produce products of $P$.

\section{Conclusions}

From the received results it can be concluded that a surface aggregation of anion-active colloidal and other soluble substances around cellulosic surfaces is initialised by use of oligomeric activating agent followed by dramatically increasing of adsorption capacity of modified cellulosic fibres. This sorption phenomenon in connection with mechanical entrapment of separated particles enables us to receive a filter material with outstanding filtration parameters, i.e. filter with both of excellent separation efficiency and relative good through-flow performance.

By optimal combination of filter and sorption phenomenon, we can receive a filter product with advantage filtration properties but without their ailments as:

1) A low separation efficiency of filter sheets due to channelling.

2) A regularly pores choking up.

3) A limited extent of high separation efficiency, because limited sorption capacity of filter sheet.

\section{Acknowledgements}

This work was supported by the Ministry of Education, Youth and Sports of the Czech Republic under the Research Projects VEPA EE2.3.20.0236.

\section{REFERENCES}

[1] M. Milichovský, "Sorption Filter Materials as Challenge for Separation Technology,” Proceedings of the 15th International Congress of Chemical and Process Engineering CHISA, Fluid Flow and Multiphase Systems, 2002, pp. 130-131.
[2] M. Milichovský and M. Vodeničarová, "Influence of the Activated Pulp on the Wet-Web Chemistry of Paper Machines," Cellulose Chemistry and Technology, Vol. 33, No. 5-6, 1999, pp. 503-511.

[3] M. Milichovský and B. Češek, "Surface Flocculation as a New Tool for Controlling Adsorption Processe," Adsorption Science \& Technology, Vol. 20, No. 9, 2002, pp. 883-896. http://dx.doi.org/10.1260/02636170260555796

[4] C. L. P. Dias, G. E. S. Valădao, A. C. Araujo, A. E. C. Peres and S. C. Amarante, "The Effect of Reagents on Ultrafine Iron Ore Vacuum Filtration,” Filtration + Separation, 2003, pp. 36-39.

[5] F. S. Bourgeois and G. J. Lyman, "Morphological Analysis and Modeling of Fine Coal Filter Cake Microstructure," Chemical Engineering Science, Vol. 52, No. 7, 1997, pp. 1151-1162. http://dx.doi.org/10.1016/S0009-2509(96)00475-7

[6] S. C. Amarante, A. C. Araujo, G. E. S. Valădao and A. E. C. Peres, "Cake Dewatering of Some Iron Ore Industrial Products,” Minerals and Metallurgical Processing, Vol. 19, 2002, pp. 161-164.

[7] C. C. Mwaba, "Surfactants-Enhanced Dewatering of Graphite and Hematite Suspensions," Minerals Engineering, Vol. 4, No. 1, 1991, pp. 49-62. http://dx.doi.org/10.1016/0892-6875(91)90118-F

[8] G. B. Tanny, D. K. Strong, W. G. Presswood and T. H. Meltzer, "Adsorptive Retention of Pseudomonas Diminuta by Membrane Filters," Journal of the Parenteral Drug Association, Vol. 33, No. 1, 1979, pp. 40-51.

[9] D. B. Pall, E. A. Kirnbauer and B. T. Allen, "Particulate Retention by Bacteria Retentive Membrane Filters," Colloids and Surfaces, Vol. 1, No. 3, 1980, pp. 235-256. http://dx.doi.org/10.1016/0166-6622(80)80015-1

[10] A. Mureșan, M. Vâța, L. Tătaru, R. Mureșan and Cr. I. Simionescu, "Modification of the Tinctorial Capacity of Cellulosic Fibers through Cationization. I. Obtention of Cationized Cellulosic Fibers," Cellulose Chemistry and Technology, Vol. 31, No. 1, 1997, pp. 17-23.

[11] A. Mureşan, M. Vâța, L. Tătaru, R. Mureşan and Cr. I. Simionescu, "Modification of the Tinctorial Capacity of Cellulosic Fibers through Cationization," Cellulose Chemistry and Technology, Vol. 31, No. 2, 1997, pp. 185191.

[12] M. Filipi and M. Milichovský, “Adsorption Characteristic of Oxycellulose in a Competitive Environment with Other Substance," Adsorption Science \& Technology, Vol. 26, No. 7, 2008, pp. 545-561.

[13] M. Foglarova, J. Prokop and M. Milichovsky, “Oxidized Cellulose: An Application in the Form of Sorption Filter Materials,” Journal of Applied Polymer Science, Vol. 112, No. 2, 2009, pp. 669-678. http://dx.doi.org/10.1002/app.29465

[14] T. Saito and A. Isogai, "Ion-Exchange Behaviour of Carboxylate Groups in Fibrous Oxidized Celluloses Prepared by TEMPO-Mediated System," Carbohydrate Polymers, Vol. 61, No. 2, 2005, pp. 183-190. http://dx.doi.org/10.1016/j.carbpol.2005.04.009

[15] R. Saliba, H. Gauthier, R. Gauthier and M. Petit-Ramel, "The Use of Amidooximated Cellulose for the Removal 
of Metals Ions and Dyes from Waste Water," Cellulose, Vol. 9, No. 1, 2002, pp. 183-191. http://dx.doi.org/10.1023/A:1020117032406

[16] R. Saliba, H. Gauthier and R. Gauthier, “Adsorption of Heavy Metal Ions on Virgin and Chemically-Modified Lignocellulosic Materials,” Adsorption Science \& Technology, Vol. 23, No. 4, 2005, pp. 313-322. http://dx.doi.org/10.1260/0263617054770039

[17] A. M. A. Nada and N. A. El-Wakil, "Molecular Structure and Ion Exchange of Amidoximated Cellulosic Materials," Journal of Applied Polymer Science,Vol. 102, No. 1, 2006, pp. 303-311. http://dx.doi.org/10.1002/app.23802

[18] B. Češek and M. Milichovský, "Releasing of Soluble and Colloidal Substances in Pulp Slurries,” Cellulose Chemistry and Technology, Vol. 30, No. 3-4, 1996, pp. 297306.

[19] B. Češek, M. Milichovský and F. Potůček, "Kinetics of
Vapour Diffusion and Condensation in Natural Porous Cellulosic Fibre Web,” ISRN Materials Science, Vol. 2011, 2011, Article ID: 794306. http://dx.doi.org/10.5402/2011/794306

[20] M. Vodeničarová, M. Milichovský and B. Češek, "Influence of Modified Pulp during Some Adsorption Processes," Cellulose Chemistry and Technology, Vol. 35, No. 1-2, 2001, pp. 59-71.

[21] M. El-Sakhawy and M. Milichovský, “Oxycellulose Modification,” Polymer International, Vol. 49, No. 8, 2000, pp. 839-844.

http://dx.doi.org/10.1002/1097-0126(200008)49:8<839:: AID-PI463>3.0.CO;2-T

[22] M. El-Sakhawy, "Characterization of Modified Oxycellulose," Journal of Thermal Analysis and Calorimetry, Vol. 63, No. 5, 2001, pp. 549-558. http://dx.doi.org/10.1023/A:1010150122848 